\title{
A TUTELA DO EMBRIÃO IN VITRO NA CONVENÇÃO AMERICANA DE DIREITOS HUMANOS: UMA INTERPRETAÇÃO DA CORTE INTERAMERICANA DE DIREITOS HUMANOS
}

\author{
Alessandro Severino Valler Zenni ${ }^{1}$ \\ Daniela Menengoti Gonçalves Ribeiro ${ }^{2}$ \\ Fernanda Diniz Aires ${ }^{3}$
}

\section{Resumo}

O caso "Artavia e Murillo e Outros" foi a primeira condenação do Estado da Costa Rica pela Corte Interamericana de Direitos Humanos, em que se discutiu o início da proteção da vida dos (pré) embriões humanos (in vitro), ou seja, a interpretação do artigo 4.1 da Convenção Americana de Direitos Humanos e a definição da expressão "em geral, desde a concepção". Este trabalho tem por objetivo estabelecer o alcance da proteção da vida humana pelo Sistema Interamericano de Direitos Humanos, a partir do método predominantemente dedutivo, por meio da análise da decisão da Corte Interamericana dos Direitos e da revisão bibliográfica de diversos periódicos, livros e trabalhos publicados sobre o tema. Por fim, objetiva-se demonstrar que o princípio da dignidade humana deve ser sempre o parâmetro para a utilização das técnicas de reprodução humana assistida, ainda que insuficiente ou ausente uma legislação nacional sobre assunto.

Palavras-chave: Embrião in vitro; Corte Interamericana de Direitos Humanos; Convenção Americana de Direitos Humanos; Nidação; Vida.

\section{INTRODUÇÃO}

Dentre as técnicas médicas que se desenvolveram no século passado, as técnicas de reprodução humana assistida destacam-se pela reviravolta que causaram nos conceitos de concepção e de início da vida humana, tornando evidente a necessidade de imposição de limites à atividade científica, sem, contudo, inviabilizá-la.

\footnotetext{
${ }^{1}$ Professor titular em Direito e Processo do Trabalho da Universidade Estadual de Maringá. Professor da Faculdade de Ciências Sociais Aplicadas de Cascavel Univel. Professor titular - Faculdades Maringá. Professor da União de Faculdades Metropolitana de Maringá. Professor do Programa de Mestrado e Ciências Jurídicas do Centro Universitário de Maringá. Pós-Doutor na Universidade de Lisboa.E-mail: asvzenni@hotmail.com

2 Professora do Programa de Mestrado em Ciências Jurídicas e da graduação em Direito do Centro Universitário de Maringá (UNICESUMAR). Coordenadora/Líder do Grupos de Pesquisa (CNPq): Instrumentos jurisdicionais de efetivação dos direitos da personalidade Pesquisadora do Instituto Cesumar de Ciência, Tecnologia e Inovação (ICETI). Doutora em Direito-Relações Econômicas Internacionais pela Pontifícia Universidade Católica de São Paulo (PUC/SP) com período de pesquisa (doutorado sanduíche) na Université Paris 1 - Panthéon-Sorbonne, França. E-mail: daniela.ribeiro@gmail.com

${ }^{3}$ Mestranda do Programa de Mestrado em Ciências Jurídicas do Centro Universitário de Maringá (UNICESUMAR). E-mail: ferdinizaires@gmail.com.
} 
As técnicas de reprodução assistida, incluindo a fertilização in vitro, eram reguladas no Estado da Costa Rica pelo Decreto Executivo no 24029-S, de 03 de fevereiro de 1995, emitido pelo Ministério da Saúde em Costa. Contudo, a fertilização in vitro foi praticada na Costa Rica apenas entre os anos de 1995 e 2000.

Isso porque, a utilização dessa técnica foi declarada inconstitucional pela Sala Constitucional da Costa Rica, em 15 de março de 2000, quando muitos casais foram impedidos de continuarem ou iniciarem o tratamento para infertilidade a partir da fertilização in vitro. A inconstitucionalidade foi arguida, em 7 de Abril de 1995, por Hermes Navarro del Valle, ao argumentar que a técnica de fertilização in vitro e transferência de embriões, regulamentada pelo referido decreto, violaria o direito à vida e a dignidade do ser humano.

Então, o Tribunal Constitucional decidiu que a aplicação da FIV, em razão da elevada taxa de perdas embrionárias, seria incompatível com a dignidade da pessoa humana e com o direito à vida do embrião, tendo em vista que essa proteção deveria ser absoluta desde o momento da fecundação. Por fim, a Sala Constitucional condicionou a realização da FIV naquele Estado à inexistência de perda embrionária, implicando em uma proibição absoluta da sua utilização, tendo em vista que mesmo após doze anos daquela decisão, essa técnica ainda não estava sendo utilizada em Costa Rica. Isto porque, mesmo após tanto avanço tecnológico, não há possibilidade de utilização da técnica sem nenhuma perda embrionária.

Diante disso, em razão do impacto da decisão nos planos de vida de vários casais que vislumbravam nas técnicas de fertilização in vitro, mesmo após o diagnóstico de infertilidade, a possibilidade de engravidarem, a situação da proibição da técnica de fertilização in vitro foi submetida à Corte Interamericana de Direitos Humanos. À Corte Interamericana de Direitos Humanos coube a tarefa de determinar o alcance da proteção à vida conferida pelo artigo $4^{\circ}$ do pacto, em especial com relação aos outros direitos igualmente protegidos, como direito à liberdade, à autonomia privada, ao planejamento familiar e direitos reprodutivos. Diante disso, o presente trabalho tem por objetivo, por meio da dedução como metodologia de abordagem, realizada a partir do estudo da sentença da Corte Interamericana de Direitos Humanos e da revisão bibliográfica sobre o tema, estabelecer o momento inicial de proteção da vida humana dependente pelo Sistema Interamericano de Direitos Humanos. Além disso, ressaltar a importância do princípio da dignidade humana como parâmetro de interpretação e limitação das para prática das técnicas de reprodução humana assistida, mesmo quando insuficiente ou ausente uma legislação nacional sobre assunto.

\section{ASPECTOS MÉDICO-BIOLÓGICOS DO DESENVOLVIMENTO HUMANO: DELIMITAÇÃO CONCEITUAL (ÓVULO FECUNDADO, PRÉ-EMBRIÃO, EMBRIÃO E FETO)}

Quando da realização da fertilização in vitro (FIV), os embriões se desenvolvem em cinco etapas, em um 
período de até cinco dias. Em um primeiro momento, os óvulos maduros são extraídos da mulher, após a indução à ovulação, selecionados e, em seguida, fecundados em laboratório, permitindo o surgimento do zigoto. Nas primeiras 26 horas de desenvolvimento, o zigoto (óvulo fecundado pelo espermatozoide) divide-se em duas células, que, no segundo dia, divide-se em quatro células, e, no terceiro dia, sucessivamente, volta a se dividir em oito células. No quarto dia, chega-se ao estágio denominado "mórula" e, no quinto dia, alcança o estágio denominado "blastocisto". Nesse período, o tamanho do pré-embrião permanece inalterado, modificando apenas a quantidade de células e suas respectivas dimensões de forma inversamente proporcional.

Cumpre observar que desenvolvimento humano embrionário se inicia quando o óvulo é fecundado pelo espermatozoide, a partir desse momento muitas alterações (divisões) transformam uma única célula em um organismo multicelular dotado de toda carga genética humana. Este primeiro estágio de desenvolvimento embrionário é denominado zigoto, que deriva da palavra grega zygotos, que significa unido, uma referência a união do espermatozoide com o óvulo.

Após sucessivas divisões, a implantação do pré-embrião, que se iniciou na primeira semana de desenvolvimento, se completará com o fim da segunda semana. Será somente com a implantação do blastocisto no útero, fenômeno denominado de "nidação", que haverá produção de hCG suficiente para possibilitar o exame de gravidez idôneo. Isto porque, os testes de gravidez são baseados na quantidade desse hormônio denominado hCG e que só estará em quantidade suficiente para possibilitar um resultado positivo e confiável de gravidez com o fim da nidação, ou seja, mais ou menos, na segunda semana após a ovulação/fecundação.

Diante disso é possível afirmar que somente após a completa fixação do pré-embrião no útero materno é ocorrerá o atraso da menstruação e que será possível a confirmação da gravidez por meio de um teste fidedigno. Até o fim da nidação, ainda que por meio de controle da data da ovulação ou da data da realização da transferência do embrião para o útero, não será possível saber com certeza se há gravidez em curso.

Ressalta-se que na reprodução assistida, os embriões podem se desenvolver em laboratórios por até cinco dias, quando podem ser transferidos para o útero da mulher ou podem ser criopreservados. A transferência embrionária para as trompas de falópio ou diretamente para o útero pode ocorrer desde o segundo dia até o quinto dia de desenvolvimento. Aproximadamente aos 12 dias, após a transferência embrionária e com a fixação do pré-embrião ao útero materno, será possível saber se a mulher ficou grávida através do exame de gravidez.

O início da fase embrionária propriamente dita ocorre com a fixação do embrião no útero materno (nidação) e refere-se ao desenvolvimento humano até a oitava semana, época na qual já estão presentes as principais estruturas. Até a nidação, o pré-embrião é um aglomerado de células dotado de carga genética humana e que no processo de diferenciação e divisão celular dará origem tanto ao embrião humano quanto aos anexos embrionários (placenta, cordão umbilical, etc). Na fase pré-embrionária não é possível saber quais células darão 
origem ao ser humano (embrião) ou aos anexos embrionários, que por sua vez também são necessários ao desenvolvimento. Ainda, não é possível saber se é o pré-embrião (aglomerado de células indiferenciadas) dará origem a apenas um embrião ou, no caso de gestação de gêmeos, a mais de um embrião.

Além disso, é importante ressaltar que, tanto na reprodução natural quanto na reprodução assistida, uma grande quantidade de pré-embriões são abortados espontaneamente e a mulher nem mesmo chega a saber se ficou grávida, tendo em vista que o sangramento pode ser confundido com a própria menstruação. Os estágios iniciais da implantação do pré-embrião são períodos críticos do desenvolvimento humano que podem não ocorrer devido à produção inadequada de progesterona e estrógeno. Portanto, a mulher que teve seu período menstrual atrasado, após relações sexuais no período de ovulação ou uso de técnicas de reprodução assistida, por vários dias e o fluxo menstrual aumentado, provavelmente pode ter sofrido um aborto espontâneo precoce. Embora de difícil apuração da taxa de abortos espontâneos até a nidação, mesmo nos processos naturais de reprodução humana, já que a mulher nem chega a ter conhecimento da gravidez, sabe-se que é elevada ${ }^{4}$.

Após o período embrionário (até a oitava semana), o ser humano em desenvolvimento é chamado de feto. Durante o período fetal, ou seja, da nona semana até o nascimento, ocorre o crescimento e a diferenciação dos tecidos e órgãos formados durante o período embrionário. É a fase em que o crescimento corporal e a maturação dos órgãos se tornam notáveis, ganhando relevância especial durante o terceiro e quarto mês.

Após essa breve explicação, é importante que fique claro ao leitor que o pré-embrião constitui uma etapa do desenvolvimento embrionário humano compreendido pelo período de formação do zigoto (óvulo fecundado pelo espermatozoide) até a nidação (fixação) no útero materno que ocorre cerca de duas semanas após a fecundação (entre 12 a 14 dias do desenvolvimento embrionário). Também é importante a compreensão de que, até esta fase embrionária, não se iniciou o processo de diferenciação celular, ou seja, o pré-embrião humano constitui um aglomerado de células indiferenciadas que poderão dar origem a um ou mais embriões (gravidez múltipla) e, ainda, aos anexos embrionários. Por isso, quando se fala em pré-embrião, não é possível definir e delimitar quais células poderão dar origem a um ser humano, isto quando a reprodução humana ocorre de forma satisfatória, ou seja, quando após a implantação haverá uma gravidez em curso. Por outro lado, o pré-embrião possui toda a carga genética humana, ou seja, possui o patrimônio genético humano, ainda que, por qualquer motivo, não venha a dar origem a um ser humano.

\footnotetext{
4 "Hertig (1975), estudando histologicamente ovos fertilizados, conclui que durante um período menstrual, a probabilidade de abortamento é $27,6 \%$. Observa-se que muitas mulheres desconhecem o estado gravídico e não imaginam seja a menstruação abundante, atrasada, na verdade, seja um abortamento subclínico”. REZENDE, Jorge de. Obstetrícia. 9. ed. Rio de Janeiro: Guanabara Koogan S.A., 2000, p. 716. "É bem provável que tais pacientes tenham tido um aborto espontâneo precoce; portanto, acredita-se que a proporção de aborto espontâneo seja em torno de 45\%. Os abortamentos espontâneos precoces ocorrem por uma variedade de razoes, uma delas é a presença de anormalidades cromossômicas.” MOORE, Keith. Embriologia básica. Tradução: Maria das Graças Fernandes Sales. Rio de Janeiro: Elsevier, 2004, p. 34
} 


\section{TÉCNICAS DE REPRODUÇÃO ASSISTIDA}

As técnicas de reprodução assistida são diferentes procedimentos médicos utilizados para auxiliar casais inférteis. Essas técnicas estão compreendidas por diferentes tratamentos para aqueles que são acometidos por alguma causa (das mais variadas possíveis) que os impossibilitam de alcançarem uma gravidez pelos métodos naturais. O diagnóstico de infertilidade, de acordo com a Organização Mundial de Saúde (OSM) é dado após a manutenção de relações sexuais desprotegidas por mais de um ano sem que ocorra a gravidez (RAIMUNDO, 2015).

Esses tratamentos podem ser utilizados no combate à esterilidade feminina ou masculina e podem envolver ou não a manipulação de gametas e/ou embriões. Isto porque, por exemplo, na inseminação artificial ocorre a implantação de gametas masculinos (espermatozoides) de forma artificial no útero da mulher, e somente ali ocorrerá a fecundação do óvulo, ou seja, a formação do zigoto ocorrerá in vivo. Enquanto, na fertilização in vitro o procedimento é mais complexo, pois haverá a manipulação de gametas e a fecundação do óvulo pelo espermatozoide acontecerá em laboratório e, a partir de então, o pré-embrião poderá ser transferido para o útero materno ${ }^{5}$.

A inglesa Louise Brown, nascida em 25 de julho de 1978, no Hospital Geral de Oldham, perto de Manchester, foi o primeiro bebê de proveta do mundo. Sua mãe, a Sra. Leslie Brown, possuía um bloqueio nas tubas uterinas, e somente conseguiu engravidar após o auxílio do embriologista Robert Edwards e o ginecologista Patrick Steptoe. Em 7 de outubro de 1984, Anna Paula Caldeira foi a primeira pessoa nascida no Brasil, fruto das técnicas de reprodução assistida, realizada pelo ginecologista Milton Nakamura, pioneiro da fertilização in vitro no país. Sua mãe, Sra Ilza Maria, já tinha quatro filhos e não podia mais engravidar. Ao casar pela segunda vez, ela e o marido decidiram ter outro filho (MOURA; SOUZA; SCHEFFER, 2009, p. 36).

A humanidade foi testemunha de avanços inimagináveis no campo da reprodução assistida. A partir de 1978, com o nascimento de Louise Brown e após a disseminação da técnica da injeção intracitoplasmática de

\footnotetext{
${ }^{5}$ As técnicas ou procedimentos de reprodução assistida são um grupo de diferentes tratamentos médicos que são utilizados para ajudar as pessoas e casais inférteis a conseguir uma gravidez, os quais incluem "a manipulação, tanto de ovócitos como de espermatozoides, ou embriões [...] para o estabelecimento de uma gravidez". Entre estas técnicas se encontram a FIV, a transferência de embriões, a transferência intratubária de gametas, a transferência intratubária de zigotos, a transferência intratubária de embriões, a criopreservação de ovócitos e embriões, a doação de ovócitos e embriões, e a maternidade de substituição. As técnicas de reprodução assistida não incluem a inseminação assistida ou artificial. Por sua vez, a FIV é "um procedimento no qual os óvulos de uma mulher são removidos de seus ovários, e são então fertilizados com esperma em um procedimento de laboratório. Uma vez concluído isso, o óvulo fertilizado (embrião) é devolvido ao útero da mulher". Esta técnica é aplicada quando a infertilidade se deve à ausência ou bloqueio das trompas de Falópio da mulher, ou seja, quando um óvulo não pode passar para as trompas de Falópio para ser fertilizado e posteriormente implantado no útero, ou em casos onde a infertilidade recai no parceiro de sexo masculino, bem como nos casos em que a causa da infertilidade é desconhecida. As fases durante a FIV são as seguintes: i) indução à ovulação; ii) aspiração dos óvulos contidos nos ovários; iii) inseminação de óvulos com espermatozoides; iv) observação do processo de fecundação e incubação dos embriões, e v) transferência embrionária ao útero materno.
} 
espermatozoides, o potencial das técnicas de reprodução assistida, aliada à engenharia genética, tem se mostrado aparentemente ilimitado. Isto tudo, intensifica vários questionamentos, principalmente, acerca de questões fundamentais relacionadas à genética, ao diagnóstico pré-implantatório, à seleção de embriões, à manipulação e à pesquisa de embriões excedentes, ao descarte de embriões criopreservados, à redução embrionária (aborto), à clonagem terapêutica e reprodutiva.

\section{CONTEXTUALIZAÇÃO DA CONTROVÉRSIA: DA SUBMISSÃO DO CASO A COMISSÃO INTERAMERICANA DE DIREITOS HUMANOS}

O Decreto Executivo n 24029-S, do Estado da Costa Rica, de 3 de fevereiro de 1995, emitido pelo Ministério de Saúde, autorizava a prática da FIV para casais conjugais e regulamentava sua execução naquele país ${ }^{6}$. Ocorre que a técnica de fertilização in vitro (FIV) foi declarada inconstitucional pela Sala Constitucional da Costa Rica em 15 de março de $2000^{7}$. Sendo assim, esta técnica foi realizada naquele Estado entre os anos de 1995 e 2000, pelo Instituto Costariquenho de Infertilidade e, neste período, nasceram 15 crianças.

A sentença da Sala Constitucional do Estado da Costa Rica declarou procedente a ação direta de inconstitucionalidade anulando o decreto que regulamentava essa técnica de reprodução assistida (FIV) e,

\footnotetext{
${ }^{6} \mathrm{O}$ Decreto Executivo, em seu artigo primeiro, regulamentava a realização de técnicas de reprodução assistida entre cônjuges, e estabelecia regras para sua realização. Enquanto no artigo $2^{\circ}$ eram definidas as técnicas de reprodução assistida como "todas aquelas técnicas artificiais nas quais a união do óvulo e do espermatozoide é conseguida por meio de uma forma de manipulação direta das células germinais em laboratório". CORTE IDH. CASO ARTAVIA MURILLO E OUTROS ("FECUNDAÇÃO IN VITRO”) VS. COSTA RICA. Sentença de 28 de novembro de 2012. Disponível em: <http://www.corteidh.or.cr/docs/casos/articulos/seriec_257_por.pdf>. Acesso em 10 maio 2017.

${ }^{7}$ Em conformidade com o artigo 75 da Lei da Jurisdição Constitucional, qualquer cidadão pode interpor a ação de inconstitucionalidade contra uma norma "quando, em virtude da natureza do assunto, não exista lesão individual e direta, ou se trate da defesa de interesses difusos ou que concernem à coletividade em seu conjunto". Baseando-se nesta norma, em 7 de abril de 1995, o senhor Hermes Navarro del Valle apresentou uma ação de inconstitucionalidade contra o Decreto Executivo que regulamentava a FIV na Costa Rica, utilizando diversas alegações sobre violação do direito à vida. O solicitante requereu que: i) o Decreto fosse declarado inconstitucional por violar o direito à vida; ii) fosse declarada inconstitucional a prática da fecundação in vitro, e iii) "sejam instruídas as autoridades públicas a manter um controle minucioso da prática médica, para que estes atos não voltem a ocorrer". Entre os argumentos alegados na ação de constitucionalidade se encontram os seguintes: i) "a porcentagem de malformações em geral foi maior que o registrado na fecundação natural”; ii) "a prática generalizada [da FIV] viola a vida humana [e] em razão das características privadas e isoladas [...] em que ocorre esta inseminação, qualquer regulamentação seria de difícil implementação e de difícil controle pelo Estado"; iii) "[a] vida humana se inicia desde o momento da fecundação, portanto, qualquer eliminação ou destruição de concebidos - voluntária ou derivada da imperícia do médico ou da inexatidão da técnica utilizada - resultaria em uma evidente violação ao direito à vida contido" na Constituição costarriquenha; iv) foi feita referência à Convenção Americana sobre Direitos Humanos, ao Pacto Internacional sobre Direitos Civis e Políticos e à Convenção sobre os Direitos da Criança; v) foi argumentado que "a fecundação in vitro [é] um negócio, [...] não cura [...] uma doença[,] nem [é] um tratamento de emergência para salvar uma vida”, e vi) “é tão violatório eliminar concebidos[,] ou seja crianças[,] jogando-os no lixo, como eliminá-los de forma deliberada devido à falta de técnica no processo, pretendendo jogar uma espécie de 'roleta russa' com as seis crianças introduzidas na mãe". CORTE IDH. CASO ARTAVIA MURILLO E OUTROS ("FECUNDAÇÃO IN VITRO") VS. COSTA RICA. Sentença de 28 de novembro de 2012. Disponível em: <http://www.corteidh.or.cr/docs/casos/articulos/seriec_257_por.pdf>.Acesso em 10 maio 2017.
} 
consequentemente, proibindo a sua realização ${ }^{8}$, em razão da violação ao princípio da reserva legal, segundo o qual somente por meio de lei, decorrente do Poder Legislativo, pelo procedimento previsto na Constituição do Estado, seria possível estabelecer restrições aos direitos e às liberdades fundamentais. Segundo a Sala Constitucional, o Decreto Executivo regulamentava e restringia o "direito à vida e à dignidade do ser humano". Além disso, ressaltou a necessidade da aplicação do artigo 4.1 da Convenção Americana de Direitos Humanos, cuja transcrição segue abaixo, bem como de outras normativas internacionais9, protegendo o direito à vida de todos, sem exceção, inclusive daquele que está por nascer. Estabelece o artigo 4.1 da Convenção Interamericana de Direitos Humanos: "Toda pessoa tem o direito de que se respeite sua vida. Esse direito deve ser protegido pela lei e, em geral, desde o momento da concepção. Ninguém pode ser privado da vida arbitrariamente”.

Desse modo, o poder judiciário do Estado da Costa Rica concluiu que esta técnica de reprodução assistida (FIV) é incompatível com a dignidade da pessoa humana e com o direito à vida do embrião, tendo em vista que o embrião humano deve ser considerado "pessoa" desde o momento da fecundação. Assim, embrião in vitro não poderia ser tratado com objeto, seja para fins de pesquisa, submissão aos processos de seleção ou conservação em congelamento (criopreservação). Ainda, de acordo com a Sala Constitucional, não é constitucionalmente legítimo que os embriões, diga-se pré-embriões, sejam expostos a um risco desproporcional de morte, tendo em vista que o número de perdas embrionárias decorrentes das técnicas de reprodução assista é considerado excessivamente elevado ${ }^{10}$.

\footnotetext{
${ }^{8}$ Da prova disponível nos autos, a Costa Rica é o único Estado no mundo que proíbe de maneira expressa a FIV. CORTE IDH. CASO ARTAVIA MURILLO E OUTROS (“FECUNDAÇÃO IN VITRO”) VS. COSTA RICA. Sentença de 28 de novembro de 2012. Disponível em: <http://www.corteidh.or.cr/docs/casos/articulos/seriec_257_por.pdf>. p. 22. Acesso em 10 maio 2017.

${ }^{9}$ Artigo I da Declaração Americana, o artigo 3 da Declaração Universal dos Direitos Humanos, o artigo 6 do Pacto Internacional sobre Direitos Civis e Políticos e o artigo 4 da Convenção Americana. Em relação ao artigo 4 da Convenção, a Sala considerou que "este instrumento internacional dá um passo decisivo, pois tutela o direito à vida a partir do momento da concepção, ademais proíbe contundentemente impor a pena de morte a uma mulher em estado de gravidez, o que constitui uma proteção direta e, portanto, um reconhecimento pleno da personalidade jurídica e real do não nascido e de seus direitos”. Além disso, a Sala fez referência ao artigo 6 da Convenção sobre os Direitos da Criança. Sobre este ponto, a Sala concluiu que "as normas citadas impõem a obrigação de proteger o embrião contra os abusos a que pode ser submetido em um laboratório e, em especial, do mais grave deles, aquele capaz de eliminar a existência”. CORTE IDH. CASO ARTAVIA MURILLO E OUTROS ("FECUNDAÇÃO IN VITRO") VS. COSTA RICA. Sentença de 28 de novembro de 2012 . Disponível em: <http://www.corteidh.or.cr/docs/casos/articulos/seriec_257_por.pdf>.p.25-26. Acesso em 10 maio 2017.

10 "Segundo a Sala pôde constatar, a aplicação da Técnica de Fecundação in Vitro e Transferência Embrionária, na forma em que se desenvolve na atualidade, atenta contra a vida humana. Este Tribunal sabe que os avanços da ciência e da biotecnologia são tão vertiginosos que a técnica poderia chegar a ser melhorada de tal maneira que os reparos indicados aqui desapareçam. Entretanto, as condições nas quais se aplica atualmente levam a concluir que qualquer eliminação ou destruição de concebidos - voluntária ou derivada da imperícia de quem executa a técnica ou da inexatidão desta - viola seu direito à vida, visto que a técnica não é conforme com o Direito da Constituição e, por isso, o regulamento questionado é inconstitucional por infração ao artigo 21 da Constituição Política e 4 da Convenção Americana sobre Direitos Humanos. Em razão de que a técnica, considerada em si mesma, contravém o direito à vida, deve-se deixar constância expressa de que, nem sequer por norma de ordem legal é possível autorizar legitimamente sua aplicação, ao menos, insiste-se, enquanto seu desenvolvimento científico permaneça no atual estado e signifique o dano consciente de vidas humanas". CORTE IDH. CASO ARTAVIA MURILLO E OUTROS ("FECUNDAÇÃO IN VITRO”) VS.
} 
A Corte concluiu que o Tribunal do Estado da Costa Rica ao condicionar a prática da FIV no país à inexistência de perda embrionária, implicou em uma proibição absoluta da sua utilização, até porque, mesmo após doze anos da decisão (no momento da sentença da Corte Interamericana), essa técnica não estava sendo realizada na Costa Rica, pois, em que pese todo o avanço da ciência, ainda não há possibilidade da sua realização sem que exista nenhuma perda embrionária.

Diante da proibição da proibição da fertilização in vitro, vários casais que estavam realizando tratamento para infertilidade foram obrigados a cessarem o tratamento ou procurem outro país para continuá-lo. Em razão disso, o caso da proibição da realização das técnicas de reprodução assistida no Estado da Costa Rica foi levado à Comissão Interamericana de Direitos Humanos por diversos casais ${ }^{11}$, pois o Estado da Costa Rica é Estado Parte do Pacto de São José da Costa Rica desde 08 de abril de 1970 e reconheceu a competência contenciosa da Corte Interamericana de Direitos Humanos em 02 de julho de 198012.

A Comissão Interamericana de Direitos Humanos submeteu o caso à Corte Interamericana de Direitos Humanos, que, por sua vez, condenou o Estado da Costa Rica pela violação aos artigos 5.1, 7, 11.2 e 17.2 da Convenção e determinou a reparação dos danos causados.

\section{DAS CONCLUSÕES E DETERMINAÇÕES DA CORTE INTERAMERICANA DE DIREITOS HUMANOS}

A Corte Interamericana de Direitos Humanos, em primeiro lugar, optou por determinar o alcance dos direitos à vida privada e familiar e sua relação com outros direitos convencionais. Feito isso, analisou os efeitos da proibição da FIV no Estado, concluindo que a sentença da Sala Constitucional implicou em uma proibição

\footnotetext{
COSTA RICA. Sentença de 28 de novembro de 2012. Disponível em: <http://www.corteidh.or.cr/docs/casos/articulos/seriec_257_por.pdf>.Acesso em 10 maio 2017.

${ }^{11} \mathrm{O}$ representante Molina alegou que no presente caso "houve uma política consistente e sustentada por mais de 11 anos que se mantém continuada no Estado costarriquenho em relação à proibição da [FIV] e de qualquer outro método de reprodução assistida que impregnou não somente as ações e omissões de todos os poderes do Estado, mas que se estendeu a propiciar na sociedade civil um repúdio a pessoas que sofrem este tipo de incapacidade reprodutiva". Por outro lado, argumentou que "depois da decisão, as vítimas experimentaram uma estigmatização social que minou sua honra e reputação social”. Nesse sentido, argumentou que "a divulgação da proibição da FIV nos meios de comunicação e a caracterização que alguns fizeram da infertilidade foi estigmatizadora para as supostas vítimas e seu entorno, e violou seus direitos à intimidade. Além disso, alguns meios de comunicação, em suas campanhas contra a FIV, emitiram mensagens ofensivas e degradantes para os demandantes em geral, provocando danos em sua saúde mental". Acrescentou que as supostas "vítimas do caso foram julgadas pela sociedade civil em virtude da falta de informação existente sobre o tema[, razão pela qual] constantemente surgiam em diversos meios de comunicação certos juízos de valor dirigidos a menosprezar a luta dos casais com uma ampla gama de desqualificativos". CORTE IDH. CASO ARTAVIA MURILLO E OUTROS ("FECUNDAÇÃO IN VITRO") VS. COSTA RICA. Sentença de 28 de novembro de 2012. Disponível em: <http://www.corteidh.or.cr/docs/casos/articulos/seriec_257_por.pdf>.p. 43-44. Acesso em 10 maio 2017.

12 "Artigo 62 1. Todo Estado Parte pode, no momento do depósito do seu instrumento de ratificação desta Convenção ou de adesão a ela, ou em qualquer momento posterior, declarar que reconhece como obrigatória, de pleno direito e sem convenção especial, a competência da Corte em todos os casos relativos à interpretação ou aplicação desta Convenção.
} 
absoluta para realização da FIV naquele país. E, em seguida, passou a interpretar o artigo 4.1 da Convenção Americana e os termos "concepção" e "em geral". Finalmente, analisou a suposta violação dos direitos convencionais das supostas vítimas à luz de um juízo de proporcionalidade.

\section{ALCANCE DOS DIREITOS A INTEGRIDADE PESSOAL E A VIDA PRIVADA E FAMILIAR}

O artigo 11 da Convenção Americana, ao dispor sobre a proteção à honra e dignidade, garante que ninguém poderá ser objeto de ingerência arbitrárias ou abusivas, por parte do Estado ou de terceiros, em sua vida privada ou na sua família. Além disso, importante ressaltar que a Corte Interamericana de Direitos Humanos tem interpretado de forma ampla o direito à liberdade, constante do artigo 70 da Convenção Americana, que está diretamente relacionado com àquele, no sentido de que o indivíduo poderá fazer ou deixar de fazer tudo o que não for vedado pela lei. De outro modo, ao analisar ambas disposições, a Corte consignou que toda pessoa pode organizar sua vida de acordo com suas próprias convicções e opções, em respeito à liberdade, que constitui um direito humano básico. Portanto, o ser humano tem o direito de desenvolver sua personalidade e aspirações, sendo que a vida privada pode ser encarada sobre múltiplos aspectos, todos determinantes para o seu desenvolvimento.

Desse modo, o Estado da Costa Rica ao proibir a utilização da fertilização in vitro, como técnica de reprodução assistida, violou essa proteção à vida privada que abrange uma série de fatores relacionados com a dignidade do indivíduo, como por exemplo, à saúde ${ }^{13}$, à integridade física e psicológica e ao planejamento familiar. Isto porque, a decisão acerca da paternidade biológica é determinante para o livre desenvolvimento da personalidade. A referida sentença da Sala Constitucional provocou uma modificação no curso das decisões tomadas pelos casais, qual seja a de tentar ter filhos a partir da FIV. A Corte esclareceu que a interferência na vida privada e na autonomia dos casais não se deu pelo fato de que as famílias podiam ou não ter filhos, até porque apenas o acesso à técnica de FIV não poderia garantir o alcance desse objetivo, mas a ingerência se refere ao fato de inviabilizar a decisão autônoma dos casais acerca do tipo de tratamento que poderiam tentar para poder exercer seus direitos sexuais e reprodutivos. A Corte ainda observou que algumas das supostas vítimas afirmaram que uma das causas que contribuiu para o rompimento do laço matrimonial foi o impacto dessa proibição e a

\footnotetext{
${ }^{13}$ Com base nestas considerações e tendo em consideração a definição desenvolvida pela OMS segundo a qual a infertilidade é uma doença do sistema reprodutivo (par. 288 supra), a Corte considera que a infertilidade é uma limitação funcional reconhecida como uma doença e que as pessoas com infertilidade na Costa Rica, ao enfrentar as barreiras geradas pela decisão da Sala Constitucional, deviam ser consideradas protegidas pelos direitos das pessoas com deficiência, que incluem o direito de ter acesso às técnicas necessárias para resolver problemas de saúde reprodutiva. Esta condição demanda uma atenção especial para que se desenvolva a autonomia reprodutiva.
} 
impossibilidade de tentarem uma gravidez.

Assim, esses diferentes aspectos da vida privada permitiram à Corte considerar à sua relação com outros direitos também protegidos pelo Pacto de San José da Costa Rica, como por exemplo, o direito de fundar uma família, o direito à integridade física e mental, e, especificamente, os direitos reprodutivos das pessoas ${ }^{14}$.

Destarte, a Corte reafirmou que a Convenção Americana conta com dois artigos que protegem à família e o direito ao planejamento familiar de forma complementares (artigo 11.2 e 17), o que importa no reconhecimento do papel central da família e da vida familiar na existência de uma pessoa e na sociedade em geral. Sendo assim, esse direito à proteção da família impõe aos Estados, em especial, dentre outras obrigações, a favorecer, da maneira mais ampla, o desenvolvimento e o fortalecimento do núcleo familiar. Portanto, a Corte concluiu que o direito ao planejamento familiar e à proteção à família é tão básico que não pode ser derrogado, ainda que as circunstâncias sejam extremas.

Ainda, a Corte ressaltou que essa situação de proibição que impediu o acesso ao tratamento médico para exercício da autonomia reprodutiva, acarretou situações de angústia e ansiedade, que afetaram o direito à integridade pessoal, embora existisse a obrigação concreta do Estado de garantir aos seus cidadãos esse tratamento para infertilidade. Portanto, os direitos à vida privada e à integridade pessoal se encontram também direta e imediatamente vinculados com o atendimento à saúde.

Outrossim, ainda que inexistente um dispositivo expresso no que se refere à saúde reprodutiva, não deveria ter existido um menosprezo ao direito à autonomia e à liberdade reprodutiva, já que há uma conexão entre a autonomia pessoal, a liberdade reprodutiva e a integridade física e psicológica. Finalmente, a Corte salientou que esses todos esses direitos também guardam estreita relação com o direito a ter acesso à tecnologia médica necessária e beneficiar-se do progresso científico para realizar o tratamento que precisavam.

Por fim, é possível dizer, em resumo, que a corte considerou que o presente caso acaba por implicar em uma combinação de diferentes aspectos da vida privada, estão relacionados aos direitos à integridade física e mental, reprodutivos, ao planejamento familiar e acesso à tecnologia e tratamento necessários.

Portanto, a Corte concluiu que a sentença da Sala Constitucional do Estado da Costa Rica, ao gerar uma interrupção no tratamento que algumas vítimas do caso já tinham iniciado no país, ou, ainda, impelir as outras a procurarem outros países para realizar a FIV, constituíram numa interferência na vida privada e familiar, que gerou

\footnotetext{
${ }^{14}$ Em segundo lugar, o direito à vida privada se relaciona com: i) a autonomia reprodutiva, e ii) o acesso a serviços de saúde reprodutiva, o que envolve o direito de ter acesso à tecnologia médica necessária para exercer esse direito. $\mathrm{O}$ direito à autonomia reprodutiva está reconhecido também no artigo 16 e da Convenção sobre a Eliminação de todas as Formas de Discriminação contra a Mulher, segundo o qual as mulheres gozam do direito "de decidir livre e responsavelmente sobre o número de filhos e sobre o intervalo entre os nascimentos e a ter acesso à informação, à educação e aos meios que lhes permitam exercer estes direitos". Este direito é violado quando se obstaculizam os meios através dos quais uma mulher pode exercer o direito a controlar
} 
violações desproporcionais a vários direitos daqueles casais.

\section{Interpretação do artigo 4.1 da convenção americana segundo a corte interamericana de direitos humanos}

Convém relembrar, que o mais alto Tribunal da Costa Rica considerou que a realização da técnica de fertilização in vitro violaria o direito absoluto à vida do embrião humano, a partir da interpretação do artigo $4^{\circ}$ da Convenção Americana de Direitos Humanos (direito à vida), dentre outros argumentos complementares.

Contudo, a Corte Interamericana ressaltou a sua função de intérprete último da convenção ${ }^{15}$ para precisar, pela primeira vez, o alcance do direito à vida, ou seja, para analisar se existe uma obrigação dos Estados Parte de proteção absoluta à vida do embrião, nos termos fixados por pela Sala Constitucional do Estado de Costa Rica. Para tanto, a Corte avaliou o alcance dos artigos 1.2 e 4.1 da Convenção Americana em relação às palavras "pessoa", "ser humano", "concepção" e "em geral".

O artigo 4.1 da Convenção Americana dispõe que "toda pessoa tem o direito de que se respeite sua vida. Esse direito deve ser protegido pela lei e, em geral, desde o momento da concepção".

A Sala Constitucional ao decidir sobre a utilização da FIV em seu país optou pela concepção científica que considera que a vida humana tem início com a fecundação e, por sua vez, entendeu que concepção seria o momento em que o espermatozoide fecunda o óvulo e, portanto, de acordo com a Convenção Americana, a partir da fecundação haveria a necessidade de tutelar de forma absoluta a vida humana dependente.

Segundo a Corte Interamericana, no atual contexto científico, se destacam duas correntes acerca do significado do termo "concepção". Uma delas entende que a concepção ocorre com a fecundação, enquanto a outra corrente entende que ela se dá no momento da implantação embrião no útero materno. Ambas interpretações concordam em diferenciar dois momentos complementares e essenciais no desenvolvimento embrionário: a fecundação e a implantação. Diante disso, a Corte Interamericana considerou que:

Nesse sentido, a Corte entende que o termo "concepção" não pode ser compreendido como um momento ou processo excludente do corpo da mulher, em vista de que um embrião não tem nenhuma possibilidade de sobrevivência se a implantação não acontece. Prova do anterior, é que somente é possível estabelecer se foi produzida ou não uma gravidez uma vez que se implantou o óvulo fecundado no útero, ao se produzir o hormônio denominado "Gonodatropina Coriônica", que somente é detectável na mulher que tem um

sua fecundidade. Assim, a proteção à vida privada inclui o respeito às decisões de se converter em pai ou mãe, incluindo a decisão do casal de se converter em pais genéticos

${ }^{15}$ Artigo 62 3. A Corte tem competência para conhecer de qualquer caso relativo à interpretação e aplicação das disposições desta Convenção que lhe seja submetido, desde que os Estados Partes no caso tenham reconhecido ou reconheçam a referida competência, seja por declaração especial, como prevêem os incisos anteriores, seja por convenção especial. 
embrião unido a ela. Antes disso, é impossível determinar se no interior do corpo ocorreu a união entre o óvulo e um espermatozoide e se esta união se perdeu antes da implantação. Além disso, já foi afirmado que, no momento de ser redigido o artigo 4 da Convenção Americana, o dicionário da Real Academia diferenciava entre o momento da fecundação e o momento da concepção, entendendo concepção como implantação (par. 181 supra). Ao se estabelecer o pertinente na Convenção Americana não foi feita menção ao momento da fecundação.

Isto porque, embora a fecundação seja a etapa inicial e essencial do desenvolvimento humano, somente com a nidação, o embrião terá condições de se desenvolver, ou seja, ainda que o pré-embrião já tenha a carga genética humana imprescindível para o seu desenvolvimento, se não houver a implantação no útero materno, não há nenhuma possibilidade do desenvolvimento de um ser humano.

Demais disso, de acordo com a Corte a expressão "em geral", do artigo 4.1 da Convenção, está relacionado com a expressão "a partir da concepção", o que indica a possibilidade de possíveis exceções à regra geral. A expressão "em geral” foi inserida no texto da Convenção com o objetivo de conciliar as diferentes opiniões, bem como as legislações dos Estados Americanos que permitiam o aborto, sobre a formulação "desde o momento da concepção", cujas discussões foram suscitadas desde a IX Conferência Internacional Americana de Bogotá em $1948^{16}$. Diante disso, a Comissão Interamericana de Direitos Humanos decidiu introduzir a expressão "em geral" antes da formulação "desde o momento da concepção". E, mesmo após as várias manifestações de diferentes Estados, a conferência, por voto da maioria, adotou o texto submetido pela Comissão Interamericana de Direitos Humanos, cuja redação permanece a mesma até o presente momento (artigo 4.1 da Convenção Americana) 17. Portanto, a Corte conclui, no caso Baby Boy Vs. Estados Unidos da América, que os trabalhos preparatórios indicaram que não prosperaram as propostas de eliminar a expressão "em geral, desde o momento da concepção" e nem mesmo as propostas das delegações que pediam eliminar somente as palavras "em geral".

Face ao exposto, a Corte consignou que não é factível argumentar que o embrião in vitro seja titular e exerça os direitos consagrados em cada um destes artigos. Ressaltou, mais uma vez, que o termo concepção significa ato de conceber e, desse modo, só pode ocorrer dentro do corpo da mulher, ou seja, para existência da concepção há a necessidade de gravidez em curso. Por fim, a Corte concluiu que a interpretação histórica e

\footnotetext{
${ }^{16} \mathrm{O}$ texto da Convenção diz "em geral" (em regra) "desde o momento da concepção". Isso foi fruto de acordo para preservar os direitos internos de bários países que adotavam a política permissiva de aborto (no tempo da aprovação do texto). GOMES, Luiz Flavio; MAZZUOLI, Valerio de Oliveira. Comentários à convenção americana sobre direitos humanos: pacto de San José da Costa Rica. 4. ed. rev., atual e ampl. São Paulo: RT, 2013.

${ }^{17}$ No momento de ratificar a Convenção, somente o México fez uma declaração interpretativa, esclarecendo que, "em relação ao parágrafo 1 do Artigo 4, considera que a expressão 'em geral' [ ...] não constitui obrigação de adotar ou manter em vigor legislação que proteja a vida 'a partir do momento da concepção' já que esta matéria pertence ao domínio reservado dos Estados". CORTE IDH. CASO ARTAVIA MURILLO E OUTROS ("FECUNDAÇÃO IN VITRO") VS. COSTA RICA. Sentença de 28 de novembro de 2012. Disponível em: <http://www.corteidh.or.cr/docs/casos/articulos/seriec_257_por.pdf>.p. 66. Acesso em 10 maio 2017.
} 
sistemática dos antecedentes existentes no Sistema Interamericano confirma que não é possível conceder o status de pessoa humana ao embrião in vitro.

\section{OS LIMITES DA PROTEÇÃO JURÍDICA DA VIDA HUMANA DEPENDENTE: UM JUÍZO DE VIABILIDADE E PONDERAÇÃO DE DIREITOS}

A maioria dos Estados signatários do Pacto de San José da Costa Rica permite a aplicação da FIV, mesmo quando inexistente qualquer regulamentação específica. Isso significa que, no contexto da prática das técnicas de reprodução assistida, a interpretação, que predominou na maioria dos Estados Parte, foi a de que a proteção do embrião pelo artigo 4.1 da Convenção não tem o condão de impedir as técnicas de reprodução assistida ou, particularmente, a FIV. Nesse sentido, esta interpretação generalizada está intimamente relacionada ao princípio da proteção gradual incremental - e não absoluta - da vida pré-natal.

Diante da decisão da Corte acerca do alcance da proteção da vida humana dependente, é possível inferir que a finalidade do artigo 4.1 da Convenção é a proteção do direito à vida, quando não implicar em uma restrição desproporcional a outros direitos que a Convenção também resguarda. Isso porque, a cláusula "em geral" tem como objetivo permitir que diante de um conflito de direitos, seja possível invocar exceções à proteção da vida desde a concepção. Isso significa dizer que a vida não tem o caráter de valor ou de direito absoluto ${ }^{18} \mathrm{e}$ inflexível, ou seja, o direito à vida deve ser ponderado diante de outros valores, princípios e direitos.

Quando há uma colisão entre princípios ou valores, há necessidade de que o operador jurídico afaste momentaneamente a aplicação de um deles, por meio da ponderação ou balanceamento. Pode-se afirmar que o direito fundamental que deverá prevalecer será aquele que mais se aproxima da dignidade da pessoa humana, que é fundamento de justiça material de validade priori ao ordenamento. Isso impede que o princípio da dignidade da pessoa humana possa ser considerado apenas mais um interesse passível de ponderação, tendo em vista que é um critério de solução mais adequado e unificador do ordenamento jurídico. Vale ressaltar que todo preceito que contrarie o princípio da dignidade da pessoa humana está despido de força obrigatória.

Portanto, o debate em questão não é apenas sobre a natureza do zigoto ou indagação sobre início da

\footnotetext{
18 "A vida constitui a base e o fundamento de todos os demais direitos da pessoa humana. Mas mesmo sendo fundamental, ainda assim, não se trata de um direito absoluto. É um truísmo (mas válido e repetível) afirmar que não existe direito absoluto (ou totalmente absoluto). Nem sequer a expectativa em relação à vida é absoluta. A legislação brasileira (Lei 11.105/2005) permite, em casos excepcionais, o uso de células-tronco (art. $5^{\circ}$ ) e isso foi considerado constitucional pelo STF (ADI 3.510). O direito à vida, não sendo absoluto, sucumbe quando se trata da tutela de outro direito de igual valor (nas situações de legítima defesa, por exemplo, uma vida é sacrificada para a proteção de outra). Para o Código Penal, essa morte resulta justificada (CP, art. 23). De qualquer maneira, nãos e pode ignorar que o valor vida conta com prioridade (ou seja: prepondera sobre qualquer outro direito). Os Estados subscritores da Convenção Americana têm o dever de proteger a vida humana. Para isso, devem desenvolver políticas de prevenção da violência, assim como reprimir os atentados contra ela." GOMES, Luiz Flavio; MAZZUOLI, Valerio de Oliveira. Comentários à convenção americana sobre direitos humanos: pacto de San José da Costa Rica. 4. ed. rev., atual e ampl. São Paulo:
} 
personalidade humana, mas, sobretudo, acerca do direito à saúde, à integridade física, à autonomia, ao livre desenvolvimento da personalidade e ao planejamento familiar de pessoas que vislumbram na ciência a possibilidade de cura para sua infertilidade (BRASIL, ADI 3.510-0, 2011). Segundo Gisele Mendes de Carvalho, ao discorrer sobre uma decisão do Supremo Tribunal Federal comparável a decisão da Corte Interamericana de Direitos Humanos, assevera essa questão não se trata de determinar se os embriões têm ou não direito à vida, mas se esse deve ou não prevalecer quando entra em conflito com o direito à vida e à saúde ${ }^{19}$ de seres humanos já nascidos (CARVALHO, 2007, p. 15).

Diante dessa constatação não apenas lógica, mas, sobretudo, humanitária, a escolha da Corte Interamericana de Direitos Humanos não deve significar um desprezo pelos embriões in vitro, mas sim compaixão pelo sofrimento alheio e o respeito à vida, em seus vários aspectos, o que ainda é uma forma de reafirmar o compromisso por uma sociedade fraterna.

Além disso, com relação a taxa de perdas embrionárias na FIV, é possível afirmar que o número de embriões perdidos em um processo natural de gravidez também é elevado. Em síntese, tanto na gravidez natural como na fertilização in vitro há um número considerável de perdas embrionárias.

Demais disso, convém lembrar que mesmo no processo natural de reprodução humana seria inviável a proteção da vida do embrião em fase anterior à fixação no útero (nidação), face à impossibilidade de diagnóstico confiável de gravidez ${ }^{20}$. Somente a partir desse termo inicial (nidação), a proteção penal por meio do tipo penal de aborto torna-se possível, em razão da necessidade de existência do bem jurídico (vida humana) e a configuração do tipo penal subjetivo, ou seja, o conhecimento da gravidez (dolo) $)^{21}$. Isso porque, a realização de manobras

\footnotetext{
RT, 2013, p. 41.

${ }^{19}$ Direito à saúde também é um direito constitucionalmente garantido e positivado como primeiro dos direitos sociais (art. $6^{\circ}$, $\mathrm{CF} / 88$ ) e dos direitos constitutivos da seguridade social (art. 194, caput, CF), sendo direito de todo se dever do Estado assegurá-la (art. 196, CF).

${ }^{20} \mathrm{~A}$ detecção do hCG nos fluidos biológicos é o teste utilizado universalmente para o diagnóstico da gravidez. O hCG é composto de duas subunidades diferentes (alfa, beta)que isoladas, não possuem atividade biológica. A fração alfa é comum a outros hormônios glicoprotéicos (LH, FSH, TSH) e a beta é específica para cada um deles. Sendo assim, a dosagem da fração beta do hCG para o diagnóstico da gravidez evita a reação cruzada, que pode ocorrer, principalmente, com o LH. Teoricamente o hCG pode ser detectado no sangue um dia após a implantação do blastocisto, ou oito a nove dias após a ovulação. A concentração sérica de hCG no dia provável da menstruação é em torno de $100 \mathrm{mUI} / \mathrm{ml}$. Na gravidez inicial e com evolução normal, a concentração de hCG no sangue duplica a cada 1,4 a 2 dias. A partir do dia da implantação, os níveis de hCG no sangue e na urina são crescentes atingindo o pico máximo aos 60 a 70 dias. As reações falso negativas dos testes de hCG podem ocorrer quando os níveis hormonais são insuficientes, devido a gravidez muito recente, na dependência da sensibilidade do teste escolhido, e se esse é realizado na urina ou no sangue. CORRÊA, Mario Dias; MELO, Victor Hugo de; AGUIAR, Regina Amélia Lopes Pessoa de. Noções práticas de obstetrícia. 13. ed. Belo Horizonte: Coopmed, 2004.

${ }^{21}$ É devido a essa delimitação do âmbito de proteção jurídico-penal da vida humana dependente, que os métodos contraceptivos de urgência ou pós-coital21 não se enquadram no tipo penal descrito no art. 124 do Código Penal. Os métodos em questão são: contracepção hormonal de urgência (método Yuzpe e levonorgestrel) e dispositivo intra-uterino de cobre, que inibem ou retardam a ovulação e quando essa já ocorreu, alteram a parede do endométrio impedindo a fixação do ovo no útero materno. A pílula de urgência pode ser administrada com eficácia até 72 horas pós-coito, após esse lapso temporal poderá ser utilizado o DIU até o $5^{\circ}$ dia, em nenhum caso alcança o termo inicial do conceito doutrinário de aborto.
} 
abortivas em mulher não grávida, em razão da absoluta impropriedade do objeto, deverá ser considerada crime impossível (PRADO, 2007, p. 114-116).

No processo natural de reprodução humana, quando o óvulo é fecundado, mas acaba por não fixar na parede do endométrio, ocorre um sangramento, que, muitas vezes é confundido com menstruação, por isso muitas mulheres nem chegam a ter conhecimento de que estava em curso uma possível gravidez. Diante desse rigoroso processo de seleção natural, o qual é submetido o embrião pré-implantatório, a proteção do Estado se torna socialmente desnecessária, em especial pela sua inviabilidade (MALANDA, 2006, p. 33-35).

Portanto, os (pré) embriões in vitro (até o $5^{\text {a }}$ dia de desenvolvimento), apesar de serem portadores do genoma humano, não podem ser considerados titulares do direito à vida de forma absoluta, dentre todos os motivos já expostos, também, em razão da impossibilidade da concessão de igual proteção aos pré-embriões resultantes do processo natural de reprodução humana.

Essa identidade genética definida desde a fecundação constitui uma condição necessária, mas não é suficiente para possibilitar a proteção da vida do projeto de ser humano. Falta aos pré-embriões a condição ambiental imprescindível para adquirir a viabilidade (capacidade de viver): a fixação no útero materno. Embriões in vitro não são viáveis, portanto, não são podem considerados nascituros. Contudo, ainda que não possam ser considerados titulares de um direito à vida até que sejam implantados no útero, não significa que devam ficar totalmente desprotegidos e submetidos a fins meramente especulativos, pois não se tratam de meros objetos ${ }^{22}$.

Como já comentado, não há dúvida que o desenvolvimento humano começa com a fecundação, mas o início da proteção jurídica se dá em momento diferente. A partir desse momento a vida humana do embrião ganha magnitude suficiente para orientar a atividade jurídica, pois essa é a condição ambiental necessária para o desenvolvimento embrionário. Diante disso, é possível afirmar que a nidação é o momento em que o embrião se encontra definitivamente no útero materno tornando-se efetivamente um nascituro (aquele que tem aptidão para nascer) (MALANDA, 2006, p. 127).

No Brasil a questão sobre a titularidade do direito à vida de embriões in vitro passou pelo crivo do Supremo Tribunal Federal, quando definiu como válida e constitucional a Lei de Biossegurança (Lei 11.105/05), que permitiu a pesquisa com células-tronco embrionárias. A questão foi levada à Corte Suprema do Brasil por meio da ADI n 3.510, proposta pela Procuradoria-Geral da República, que arguiu inconstitucionalidade do artigo $5^{\circ}$ da Lei no $11.105 / 2005$ por violar o direito à vida do embrião in vitro.

\footnotetext{
22 "Pero tampoco cabe otorgarle la categoría de cosa (no es sujeto, pero tampoco es objeto), pues es un no-sujeto de derecho abocado, por un proceso evolutivo, a convertirse en un sujeto de derecho. Sería erróneo, asimismo, concerderle un estatuto jurídico intermedio entre una y otra categoría- persona y cosa-, sino que debe reconocérsele un estatuto diferente, autónomo, en un plano coherente con la gradación valorativa expuesta; es decir una tercera vía, diferente de las anteriores, pero no meramente intermedia,
} 
Quanto à titularidade do direito à vida, o STF entendeu que a Constituição Federal do Brasil tem como destinatário dos direitos fundamentais o indivíduo-pessoa, que compreende todo ser humano já nascido, de nacionalidade brasileira (em alusão aos brasileiros natos e aos naturalizados) e estrangeiros, deixando expressa a condição de residir no país, e não fazendo menção sobre útero materno ou tubo de ensaio ou "placa de Petri". Conclui o Ministro Ayres Britto:

Numa primeira síntese, então, é de se concluir que a Constituição Federal não faz de todo e qualquer estágio da vida humana um autonomizado bem jurídico, mas a vida que já é própria de uma concreta pessoa, porque nativiva e, nessa condição, dotada de compostura física ou natural. É como dizer: a inviolabilidade de que trata o artigo $5^{\circ}$ é exclusivamente reportante a um já personalizado indivíduo (o inviolável é, para o direito, o que é sagrado para a religião). E como se trata de uma Constituição que sobre o inicio da vida humana é de um silêncio de morte (permito-me o trocadilho), a questão não reside exatamente em se determinar o início da vida do homo sapiens, mas em saber que aspectos ou momentos dessa vida estão validamente protegidos pelo Direito infraconstitucional e em que medida (BRASIL, ADI 3.510-0, 2011).

Segundo Romeo Malanda, a orientação do Tribunal Constitucional Espanhol sobre a titularidade do direito à vida foi no mesmo sentido, ou seja, excluiu da proteção constitucional de forma direta a vida humana dependente. Veja-se:

Uma das principais questões levantadas no apelo era se o art.15 CE (Todos tem o direito à vida) abrange também a vida do feto ou, inversamente, se refere apenas a vida das pessoas já nascidas, apenas mais claramente escolheu o Projeto Constituição (Você tem o direito à vida). O Tribunal Constitucional resolve o problema, afirmando categoricamente que o nascituro não é titular do direito fundamental à vida. No entanto, isso não o impede de ser legalmente protegida por essa arte. 15 (cf., FF.JJ. 5 e 7) porque a vida humana é um tornando-se, um processo que começa com a gestação, durante o qual uma realidade biológica leva significativamente corpórea configuração humano, e que termina na morte, é em tempo contínuo efeitos apresentados por mudança qualitativas de natureza somática e psicológica que se refletem no estatuto jurídico público ou privado da vida (2006, p. 66).

Percebe-se claramente que a preocupação desses Tribunais não foi fixar o momento que inicia a vida humana, constatação puramente físico-biológica, mas em determinar quando ela começa a receber proteção jurídica e se torna um bem jurídico constitucional. Fica evidente que de acordo com as concepções adotadas por estes Tribunais, o nascituro, conceituado legalmente como aquele que tem aptidão para nascer, não é titular do bem jurídico explícito (direito à vida) garantido constitucionalmente. Todavia, se a Constituição protege a vida independente, não poderia deixar de proteger na etapa que não é apenas condição posterior dela, como também um momento do desenvolvimento da vida em si mesma. Por consequência, pode-se dizer que a vida do nascituro constitui um bem jurídico que encontra seu fundamento último na Constituição, o que segundo Sergio Malanda

entre persona y cosa". CASABONA, Carlos María Romeu. El derecho a la vida: aspectos constitucionales de las nuevas biotecnologías. Actas de las VIII Jornadas de la Asociación de Letrados del Tribunal Constitucional, Madrid, 2003, p. 30. 
é um bem jurídico implícito ${ }^{23}$.

É possível concluir que de acordo com a decisão desses Tribunais, incluindo a Corte Interamericana de Direitos Humanos, o (pré) embrião antes da nidação não possui o status de nascituro, tendo em vista que, ainda que ele possua toda a carga genética humana, não existem as condições ambientais necessárias para se tornar um ser humano.

E, a partir dessas mesmas premissas, é possível dizer que, a proteção do concebido, fruto de reprodução natural, só é necessária e possível, a partir da nidação. Como consequência lógica, não faz sentido, por si só, a proteção da vida de embriões in vitro ${ }^{24}$, principalmente quando essa proteção implica em violações a outros direitos considerados essenciais ao livre desenvolvimento da condição humana.

\section{CONSIDERAÇÕES FINAIS}

O judiciário do Estado da Costa Rica ao proibir a utilização da FIV por casais, que vislumbravam nessa técnica a possibilidade de superarem graves dificuldades reprodutivas e realizarem seus projetos de vida, incidiu em violações à autonomia privada, dentre vários direitos igualmente protegidos pela Convenção Americana de Direitos Humanos.

A Sala Constitucional, em síntese, fundamentou a proibição da FIV, em razão do elevado número de perdas de embriões transferidos pela FIV, na violação ao direito à vida e à dignidade da pessoa humana, que deveria ser protegido desde a fecundação.

Após a submissão do caso ao Sistema Interamericano de Proteção aos Direitos Humanos, a Corte Interamericana, ao utilizar de diversos métodos de interpretação, decidiu que o embrião in vitro não poderia ser entendido como pessoa para efeitos da proteção outorgada pelo artigo 4.1 do Pacto de San José da Costa Rica. Demais disso, a Corte concluiu que o termo "concepção", no sentido do artigo 4.1, deve ser entendido como momento em que o embrião se implanta no útero materno, e, portanto, antes da implantação não teria aplicação

\footnotetext{
23 “Una de las cuestiones clave planteadas en el recurso era la de sí el art. 15 CE (Todos tienen derecho a la vida...) abarca también a la vida del nascituruso, por el contrario, se refiere exclusivamente a la vida de las personas ya nacidas, tal y más claramente recogía el Anteproyecto de Constitución (La persona tiene derecho a la vida...). El Tribunal Constitucional resuelve la cuestión afirmando categóricamente que el nasciturus no es titular del derecho fundamental a la vida. Ahora bien, ello no impide que constituya un bien jurídico protegido por el citado art. 15 (cfr, FF. JJ. 5 y 7) pues la vida humana es un devenir, un proceso que comienza con la gestación, en el curso de la cual una realidad biológica va tomando corpórea y sensiblemente configuración humana, y que termina en la muerte; es in continuo sometido por efectos del tiempo a cambios cualitativos de naturaleza somática y psíquica que tienen un reflejo en el status jurídico público y privado del sujeto vital”. MALANDA, Sergio Romeo. Intervenciones genéticas sobre el ser humano y Derecho Penal. Consideraciones político-criminales y consecuencias dogmáticas. Bilbão: Granada, 2006, p. 123-126.

${ }^{24}$ No caso de embriões constituídos in vitro é possível, com os fatores epigenéticos disponibilizados pelo meio de cultura, conseguir um desenvolvimento embrionário durante alguns dias, até sete ou oito, atingindo, in vitro, a fase de blastocisto, mas não mais. SERRÃO, Daniel. Estatuto do embrião. Revista Bioética, América do Norte, n.12, oct. 2009. Disponível em: <http://revistabioetica.cfm.org.br/index.php/revista_bioetica/article/view/183/187>. Acesso em: 2 jun. 2017.
} 
do artigo 4.1 para fins de proteção da vida humana dependente. E, ainda, a cláusula "em geral" acarreta em uma proteção relativa ao direito à vida, que comporta exceções à regra, ou seja, a proteção conferida pela Convenção deve ser gradual e incremental segundo o desenvolvimento do ser humano, o que implica em dizer que a vida humana pode ser valorada e protegida de acordo com o seu estágio de desenvolvimento. Além disso, a Corte concluiu que a perda embrionária na reprodução natural e nas técnicas de reprodução assistida é comparável e, portanto, não seria razoável proteger, por si só a vida humana dependente antes da nidação, principalmente quando essa proteção ocasiona a violação de vários direitos personalíssimos.

Diante disso, é possível concluir que a proteção da vida humana dependente só é necessária e razoável após a implantação do embrião no útero materno, pois, somente a partir desse momento, o concebido terá as condições ambientais necessárias para o seu desenvolvimento e, provavelmente, dará origem a uma pessoa.

Portanto, os (pré) embriões in vitro, embora possuam toda carga genética humana, não são considerados titulares do direito à vida de forma absoluta, dentre todos os motivos expostos ao longo do trabalho, mas, também, em razão da impossibilidade de concessão de igual proteção aos embriões pré-implantatórios oriundos do processo natural de reprodução

Ressalta-se que a carga genética humana dos embriões pré-implantarórios não é suficiente para garantir a sua viabilidade, ou seja, falta aos pré-embriões a condição ambiental imprescindível para garantir a continuidade do seu desenvolvimento: o útero materno. Contudo, ainda que não possam ser considerados titulares de um direito à vida até que sejam implantados no útero, os embriões pré-implantatórios não podem ficar totalmente desprotegidos e ser submetidos a fins meramente especulativos, pois não se tratam de meros objetos.

\title{
THE PROTECTION OF THE EMBRYO IN VITRO IN THE AMERICAN CONVENTION ON HUMAN RIGHTS: AN INTERPRETATION OF THE INTER- AMERICAN COURT OF HUMAN RIGHTS
}

\begin{abstract}
The Artavia and Murillo et al. Case was the first conviction of the State of Costa Rica by the Inter-American Court of Human Rights, in which the beginning of the protection of human (in vitro) pre-embryos was discussed, that is, the Interpretation of Article 4.1 of the Inter-American Convention on Human Rights and the definition of the phrase "generally from the outset". The purpose of this paper is to establish the scope of the protection of human life by the Inter - American System of Human Rights, based on the predominantly deductive method, through the analysis of the decision of the Inter - American Court of Human Rights and the bibliographical revision of several periodicals, books and published works about the subject. Finally, it aims to demonstrate that the principle of human dignity must always be the parameter for the use of techniques of assisted human reproduction, even if insufficient or absent national legislation on the subject.
\end{abstract}


Keywords: In vitro embryo; Inter-American Court of Human Rights; American Convention on Human Rights; Nesting; Life.

\section{REFERENCIAS}

BRASIL. Supremo Tribunal Federal. Ação direta de inconstitucionalidade 3.510. Distrito Federal. Procurador geral da República e Presidente da República. Relator: Min. Carlos Ayres Britto. Acórdão não publicado. Disponível em: $<$ http://redir.stf.jus.br/paginadorpub/paginador.jsp?docTP=AC\&docID=611723>. Acesso em: 10 de Janeiro, 2011.

CARVALHO, Gisele Mendes de. Quando deve ter início a proteção da vida humana? (a verdadeira questão inerente ao julgamento da ADIN 3. 510 pelo STF). Boletim IBCCRIM, São Paulo, ano 15, n. 176, p. 15, jul., 2007.

CASABONA, Carlos María Romeu. El derecho a la vida: aspectos constitucionales de las nuevas biotecnologías. Actas de las VIII Jornadas de la Asociación de Letrados del Tribunal Constitucional, Madrid, 2003.

CONVENÇÃO AMERICANA DE DIREITOS HUMANOS. Assinada na Conferência Especializada Interamericana sobre Direitos Humanos, San José, Costa Rica, em 22 de novembro de 1969. Disponível em: <https://www.cidh.oas.org/basicos/portugues/c.convencao_americana.htm>. Acesso em: 2 jun. 2017.

CORRÊA, Mario Dias; MELO, Victor Hugo de; AGUIAR, Regina Amélia Lopes Pessoa de. Noções práticas de obstetrícia. 13. ed. Belo Horizonte: Coopmed, 2004.

CORTE IDH. CASO ARTAVIA MURILLO E OUTROS (“FECUNDAÇÃO IN VITRO”) VS. COSTA RICA. Sentença de 28 de novembro de 2012. Disponível em: <http://www.corteidh.or.cr/docs/casos/articulos/seriec_257_por.pdf>. Acesso em 10 maio 2017.

GOMES, Luiz Flavio; MAZZUOLI, Valerio de Oliveira. Comentários à convenção americana sobre direitos humanos: pacto de San José da Costa Rica. 4. ed. rev., atual e ampl. São Paulo: RT, 2013.

MALANDA, Sergio Romeo. Intervenciones genéticas sobre el ser humano y Derecho Penal. Consideraciones político-criminales y consecuencias dogmáticas. Bilbão: Granada, 2006.

MOORE, Keith. Embriologia básica. Tradução: Maria das Graças Fernandes Sales. Rio de Janeiro: Elsevier, 2004.

MOURA, Marisa Decat de; SOUZA, Maria do Carmo Borges de; SCHEFFER, Bruno Brum. Reprodução assistida: um pouco de história. Rev. SBPH, v. 12 n. 2, Rio de Janeiro, dez., 2009.

PRADO, Luiz Regis. Curso de Direito Penal brasileiro. Parte especial. v.2. 6 ed. São Paulo: Revista dos Tribunais, 2007.

RAIMUNDO, José Miguel. Infertilidade uma realidade atual? Revista Revisores e Auditores, out/dez 2015. Disponível em: <http://www.oroc.pt/fotos/editor2/Revista/71/Saude.pdf>. Acesso em: 15 jun. 2017.

REZENDE, Jorge de. Obstetrícia. 9. ed. Rio de Janeiro: Guanabara Koogan S.A., 2000. 
SERRÃO, Daniel. Estatuto do embrião. Revista Bioética, América do Norte, n. 12, oct. 2009. Disponível em: <http://revistabioetica.cfm.org.br/index.php/revista_bioetica/article/view/183/187>. Acesso em: 2 jun. 2017.

Trabalho enviado em 17 de julho de 2017.

Aceito em 28 de outubro de 2017. 